\title{
Inclusive innovation Democratization of innovation in Less Developed countries (LDCs)
}

\author{
llan Bijaoui ${ }^{* 1}$ \\ *1. Graduate School of Business Management | Bar Ilan University | Ramat Gan | Israel |
}

\begin{abstract}
Inclusive innovation incorporates the excluded individuals into the innovation trends and enhances the quality of life in developing nations. A proficient inclusive innovation policy ought to enhance the living conditions of most of the population living at the necessity level and lower, businesses and customers.
\end{abstract}

Keywords: Frugal, grassroot, wealth, BoP, Inclusive, LDCs

DOI: $10.7176 / J S T R / 5-6-11$

\section{Introduction}

Disparity gap amongst rich and poor, urban and rural, employed and jobless, skilled and unskilled, men and women, is growing in spite of or because of technological development. A growing population in the developing world is excluded from the values generated by innovation, or benefit of it many years after its introduction. The rich are getting richer while the poor are progressively many more.

The National Innovation Policy (NIP) in LDCs is chiefly in light of the proficient usage of foreign technology. Imported technologies support productivity, growth and diversification (UN, 2016) improving mainly the conditions of the wealthier population. Inclusive innovation generates wealth to the majority including the Bottom of the Pyramid (Bop)

(Mashelkar 2014; Codagnone 2009; OECD 2013).

The OECD (2015) characterizes three inclusive innovation models. Pro inclusive innovation model adjusts current technologies to local needs. Frugal innovation generates new development improving the living conditions. Grassroot innovation results from the initiatives of local entrepreneurs to problems seeking for easier and lower cost solutions (Betts et al, 2015; Heeksa et al, 2014).

We present NIP policy in LDCs minded for inclusive innovation and prove that inclusive innovation democratize innovation by the analysis of initiatives launches in selected domains which improve wealth of the wide majority in LDCs.

\section{Inclusive innovation policy in selected coountries}

\subsection{India}

The National Technology Council (NIC) in association with the Ministry of Micro, Small and Medium Enterprises (MSME), motivated in 2014 the India Inclusive Technology Fund (IIIF) which puts resources into wanders obliging the nation's poor (currentaffairs website). The attention is on health care, food, horticulture, and energy.

PM Rajiv Gandhi established in 2010 the NIC under the Chairmanship of Mr. Sam Pitroda to execute methodologies for inclusive innovation in India and set up a Roadmap for Technology 2010-2020 (innovationcouncilarchive website).

India's US\$1 billion Inclusive Technology Fund has financed an extensive program to support 100 Industry Technology Centers, seven Cluster Technology Centers and several Startup Villages (atelier site). 
The National Technology Council (NInC) in collaboration with the MSME and the Planning Commission of India, made TFJs a national activity.

With TFJ, kids get to de-develop (TodFod) ordinary devices that children's see or potentially utilize. As they make sense of how these items are composed and how they function. They may re-build (Jod) these items, repair (Jod) them or make something totally new. The goal is to give assets and coaches to children and teachers to make in schools and networks creative projects (NIC, 2013).

\subsection{China}

The central government started in 1986 the China Poverty Alleviation Program focused on 592 assigned poor regions and on more than 148,000 towns (World Bank, 2013). The 12th Five-Year Plan (20112015) policy was to invest in education instruction, health, transportation, sanitation, and agribusiness. Herewith some programs supporting inclusive innovation activities.

The goal of the Spark program initiated by Ministry of Science and Technology (MOST) in 1986 was to diffuse technology to rural zones with a specific end goal, to animate the development of neighborhood farming and industry (World Bank, 2013). In 2012, the National Spark Programme launched 1473 projects and in 2013, 3454 projects.

Since 2011, "Garage Café" program proposes to business persons a free open office condition. In co-peration with the Zhongguancun Branch of the Bank of Beijing, small scale credit loans for entrepreneurial projects are given.

The "Nursery Garden" program has been made by students of the Nanjing University of Posts and Telecommunications. The nursery cultivate is a start-up incubator co-set up by the college and Nanjing Gulou District Government. Its customers are fundamentally the college's students and ongoing graduates.

\subsection{Thailand}

In 1969, the King Bhumibol Adulyadej motivated the Royal projects with the targets to help development, secure common assets and stop opium generation.

Six R\&D stations in Chiang Mai have been set up, five under the directorship of Kasetsart University (KU) and one under the Department of Agriculture. The need was on organic products, vegetables, cut flowers, coffee, tea, shitake mushrooms, herbs and quickly developing species of forest trees.

The Royal Projects bolster additionally the development of streets, small water system frameworks, town power for energy security and self-improvement associations, for example, town rice banks, creation groups, town boards of trustees, and cooperatives. Small-scale canning plants were widely motivated with close research links with Chiang Mai University.

\subsection{Uganda}

The Centre for Research in Energy and Energy Conservation (CREEC) set up in 2001 develops energy management, solar photovoltaic (PV), Hydropower and Biomass projects (creec.or.ug site). The projects developed are waste to energy making charcoal fines and useable, production of charcoal-briquettes through solar drying and small-hydro-in-rural-Uganda.

Community Wireless Resource Centre (CWRC) targets is web conveyance to communities. iLabs is a communitarian inquire about the task with the Massachusetts Institute of Technology (MIT), Obafemi Awolowo University (OAU) and the University of Dar-es-Salaam. iLabs creates online research center offices.

The developments in the Bureau of Biological Sciences (BS) of Makarere university include: chemicals for normally detoxifying the body, treatments for skin contaminations, cream mosquito repellent, nutritious supplements produced using mushroom, millet and other supplement rich foods, porridge flour from simsim, millet and moringa.

\subsection{Kenya}

The University of Nairobi established in 2013 C4DLab, in collaboration with the Massachusetts Institute of Technology (MIT) (c4dlab.website).

C4DLab is a prototyping and inventive startup hatching lab at the School of Computing and Informatics, University of Nairobi. In this program Farmdrive links farmers who need financial support with investors (farmdrive.co.ke website). M-kulima utilizes the Internet of Things (IoT) to increase the efficiency of farming. (m-kulima.co.ke website).

The University of Nairobi and UNICEF began in 2016 common programs supporting youth in Kenya (UNICEF, 2016). 
eKitabu is building up an open source and cross-stage, e-reading application that gives better access to figuring out how to kids with handicaps (unicefstories website).

More than 1.5 million children's under age of 5 kick the bucket every year because of irresistible diseases like loose bowels (soapen site). SoaPen By drawing on the front, back and on the fingers, the tyke takes after the right strides of hand washing.

\section{Pro-inclusive innovation}

Pro inclusive innovation adapts and diffuses current technologies to excluded communities. Telecommunication, energy, water, health, education, and food are the primary spaces in which pro inclusive innovation happen. Herewith some cases having a wide impact on wealth in LDCs.

\subsection{Communication and broadband networks}

The Global Research Alliance (GRA) a partnership of eight research and technology associations (globalalliance site), build up a IT network, The GRA ICT4D, appropriate to give Internet access in country Sub-Sahara-Africa (fraunhofer site). The association MachaWorks bolsters the activity as a neighborhood stay point in rural Zambia. Fraunhofer Portugal AICOS contributes with the product answers for cell phones which address neighborhood requests and is steered in Zambia over the developed correspondence infrastructure.

The Omidyar Network, the brainchild of eBay (insidephilantropy site), in cooperation with Opportunity International makes and actualize new electronic and wireless financial services making microfinance accessible to more individuals in Sub-Saharan Africa (omidyar microfinance site).

NetHope (nethope website), a technology alliance of the world's 50 largest humanitarian agencies, provides affordable broadband -TV white space to rural Kenyans, Internet and power. This system utilizes TV void area (TVWS) technology and exploits unused range groups already utilized for TV broadcasting (Muraga, 2015).

M-Pesa, Kenya provides financial services using cell phones (vodaphone website). Safaricom and Western Union achieve worldwide consent to permit M-Pesa clients to get global cash exchanges from 45 nations, including the US, Canada, Italy, and the UK.

MomConnect, incorporates health messages developed by the South African National Department of Health bolstered by the master from Baby Center. MomConnect controls interfaces to guarantee that input from moms achieves the most abnormal amounts of government.

More than 95\% of centers and health offices in Sout Africa are taking part in the program. NurseConnect is utilizing a considerable lot of similar channels and strategies of MomConnect to help medical attendants and birthing specialists.

Dooit is an education application focused young ladies in school between 16-18 years of age. Dooit enables youth to set aside some cash and achieve objectives all alone. Composed inside the limitations of low-salary youth in Indonesia, for whom banks are difficult to reach or untrusted, young ladies have an individual cash coach in Dooit that aides them through the way toward defining objectives and following reserve funds. Loaded with reserve funds tips, tests, and fun difficulties, Dooit urges young ladies to build their investment funds conduct and enhance their money-related proficiency.

Mentor To Go in India suppors young ladies somewhere in the range of 15 and 18, especially in provincial and semi-urban regions. They are required to exhibit expanded fearlessness and impression of selfviability. The application for coaches associates them to their mentee by means of free calls and bolstered by an open-source back-end. The projects offer an adaptable timetable to suit ladies' duties and expert commitments, and additionally young ladies' school timings.

\subsection{Energy supply}

Siemens conveys effective microgrid management (Siemens site). In 2012 Siemens signed an agreement to give Supervisory Control and Data Acquisition (SCADA) for eight urban communities, including Mumbai, in the Indian territory of Maharashtra. Siemens introduced in excess of 4,000 remote terminal units (RTUs) at substations and along the medium-voltage framework, and connection client care and mapping frameworks to it to do things like recognizing shortcomings, coordinate blackout repairs - and spot control burglary. Several Indian state governments apparently laid plans for brilliant lattice ventures, running from savvy meter rollouts in the Indian regions of Puducherry and Bangalore, to an across the nation organization (St. John, 2012).

\subsection{Medical equipment}

$\mathrm{X}$-ray frameworks are as yet not generally accessible and just about 4.5 billion individuals in developed and developing nations need access to these frameworks (Siemens Capital Market Day, Healthcare,

83 | $P$ a g e 
2012). Siemens established the Multix Select DR, a passage level framework that encourages practical access to X-rays at a value that is around $30 \%$ lower than the regular framework. Multix Select DR is appealing to small and medium-sized doctor's facilities in developing nations and in addition to small healing centers and doctors' facilities in industrialized nations. Alongside cost viability, Siemens additionally centered on clinical proficiency and diminished the dosage or Xray prerequisites by half, which made it more secure for the patients and specialists (Siemens Capital Market Day, Healthcare, 2012). Multix is being developed in China and is getting very much acknowledged comprehensively, numerous healing centers in the developed world have begun utilizing them as backup machines as well. The principal obtaining nations are Germany, India, Brazil, and the United States.

The GE Brivo CT conveys high imaging quality and unwavering quality at low working and upkeep costs (GE, 2012). 60 percent of all township healing facilities in China with Brivo CT scanners were first time purchasers of CT scanners. Brivo XR 515/575 is the principal level board computerized X-ray framework for country medicinal services.

The US Mobisante portable ultrasound device left coordinated effort between Sailesh Chutani's previous group at Microsoft Research, and David Zar's lab at Washington University at St. Louis (mobisante website).

Mobisante has established a cell phone ultrasound test called the Mobius (technologyreview.com, medecine website). It can be utilized for fetal ultrasounds and imaging of organs like kidneys, irritate bladders, organs, and delicate tissue. Conventional ultrasound machines cost $\$ 300,000$ or more, while the MobiUS costs just $\$ 7,500$.

Siemens Fetal Heart rate Monitor (FHM) developed at Siemens India examines focus targets Indian rural market. It is a device that can screen the pulse of embryos in the womb. FHM utilizes extraordinary acoustic amplifiers advanced to keep the cost low. It was a worldwide exertion with joint endeavors crosswise over research groups in India, Germany and USA.

\section{Frugal innovation}

Frugal innovation develops tailor made solutions to specific needs raised by excluded population from pro inclusive innovation.

\subsection{Energy supply}

In 1998, Dave Irvine-Halliday, a teacher of the electrical building at the University of Calgary in Alberta, Canada started building up his own particular white LEDs or WLEDs, in light of a plan spearheaded by Nichia Corp. in Japan. Field tests in Nepal in 1999 were done and three Nepalese towns were enlightened with WLEDs (lutw.org/site). After three years, he established the Light up the World (LUTW) Infrastructure to convey LED technology to the poor on a worldwide scale. The non-benefit bunch has dispersed low-control, white LEDs requiring small to no effort to in excess of 300,000 individuals.

LEDs can be kept running on small batteries. They can convey up to 100 times more light to enlighten a region than lamp fuel lamps and they can sparkle persistently for up to 50,000 hours contrasted and just 1,000 hours for conventional brilliant lights. LEDs additionally utilize near 80 percent less energy than brilliant lights. LUTW extended their tasks to nations, for example, India, Pakistan, the Philippines, Mexico, Ghana and Peru.

In 2009 the China motivated the Golden Sun program, which gives money related sponsorships to help photovoltaic influence age exhibit ventures.

In 2011 the Golden Sun venture motivated 15 autonomous photovoltaic power plants in remote sectors without power, situated in 7 central and western areas, for example, Gansu, Qinghai, Tibet, Xinjiang, Inner Mongolia, Hunan, and Yunnan.

\subsection{Affordable electric appliances}

In China, Haier established a clothes washer show that serves additionally washing vegetables (Duysters et al, 2009).

This model, focusing on country regions, was the consequence of Haier repair men revealing back to the organization that individuals in provincial China utilize their clothes washers for cleaning vegetables, for example, potatoes. Haier has proceeded to create washers that can peel potatoes, securely wash garments normally implied for hand-washing and even plan a model for herders in Inner Mongolia and the Tibetan Plateau which enables the procedure to yak margarine (Backaler, 2010).

Chotu Kool, developed by Godrej and Boyce (G\&B), India a multi-business endeavor (godrej and boyce website) weighs just $7.8 \mathrm{~kg}$, utilizes top of the line protection to remain cool for a considerable length of time without control, and expends a large portion of the energy utilized by general iceboxes and costs just US\$69. The Chotu Kool does not utilize a blower. It keeps running on a cooling chip and a fan like

84 I P a g e

www.iiste.org 
that is utilized in PCs. The unit has just 20 sections instead of in excess of 200 sections in an ordinary fridge, making it effectively functional. The Chotocool fridge is sold in developed nations by Godrej merchants and by Amazon all other the world (amazon.in Godrej website).

\subsection{Sanitary and health devices}

PermaNet ${ }^{\circledR}$, the bed net of the Vestergaard NGO (vestergaard website) empowers the moderate arrival of the bug spray deltamethrin and avoids vector-borne infection, for example, jungle fever and malaria. To date, in excess of one billion individuals have profited from PermaNet ${ }^{\circledR}$ bed nets recognized by the World Health Organization's Vector Control Advisory Group as the first in class (malariaworld.org site). ZeroFly ${ }^{\circledR}$ Storage Bag avoids damaging pest pervasions. It lessens the loss of seed or grains. Bug spray is consolidated into singular strands of the sacks, which gives an intense slaughtering activity against putaway item bugs before they can plague the grain or seed gathered taken care of.

LifeStraw ${ }^{\circledR}$ water channels change over polluted water into spotless, safe drinking water. Safe drinking water is particularly critical for powerless groups, for example, kids under five, pregnant ladies and individuals living with HIV. LifeStraw ${ }^{\circledR}$ water channels likewise avert cryptosporidiosis, a noteworthy reason for diarrheal sickness in individuals living with HIV and kids under five.

The Tata Swach a non-electric purifier utilizes licensed Silver Nanotechnology for the cleansing of water without utilizing unsafe chemicals and with least support cost (Paunov, 2013) and tataswach website). In the Tata Swach configuration, water decontamination is done utilizing handled rice husk slag impregnated with nanosilver particles for sanitizing the water and to crush sickness causing microbes, germs, and different life forms. The bactericidal properties of silver are credited to its capacity to respond with the sulphhydryl bunches in the bacterial cells.

\subsection{Medical solutions}

On account of the meningitis antibody, PATH, a health NGO situated in Seattle, WA, focused on developing it at a cost of under US\$1. A joint effort with the Serum Institute of India brought about technology exchange to a pharmaceutical organization in a developing business sector, focused on delivering the immunization at 50 pennies a dosage. On account of the syringes, PATH obtained the protected technology behind a current item and authorized it to others depending on the prerequisite that they will be provided easily. In 2013 PATH and Janssen having a place with J\&J, went into an authorizing consent to build up the long-acting, injectable type of rilpivirine keeping from tainting of AIDS.

The historical backdrop of Embrace began in 2008, in a class at Stanford University, where the fellow benefactors were tested to think of a child hatchery that costs under $1 \%$ the cost of a conventional hatchery (US\$20,000)(embracetechnology site).

The Embrace group started their promoting investigation in Kathmandu, the capital city of Nepal. They discovered that a large portion of untimely Nepalese newborn children were conceived in country regions and not in healing facility. So their framework needs to work without power and be transportable and economical.

Embrace item utilizes an exceptional wax joined in a dozing sack to direct a child's temperature. It remains heat without power, is portable and safe. Grasp motivated the principal variant of its item in India. Clients incorporate private centers, government facilities, and NGOs. The item has helped more than 200,000 children crosswise over 20 nations. Most as of late, Embrace Technology motivated another line of infant items for the US market called Small Lotus Baby (smalllotusbaby website).

Extreme neonatal jaundice executes more than 100,000 infants every year and causes serious cerebrum harm to thousands more. Much of the time, the condition can be dealt with by basically sparkling a blue light on an infant's skin (Churchill, 2017). Be that as it may, every year in excess of 6 million newborn children worldwide do not get satisfactory treatment. The issue is especially serious in low-pay nations, where numerous healing centers can't bear the cost of the gear to treat jaundice.

Without treatment, cerebrum harm or death result. Presenting them to blue light for a couple of days (phototherapy) take care of the issue. Phototherapy requires gear and substitution of knobs at present. DRev developed Brilliance LEDs works sixteen to twenty-five times longer than ordinary lights (D-Rev website).

D-Rev's motivated device LEDs that last 60x longer than fluorescent lights, sparing healing centers over $\$ 240$ every year on substitution knobs. Brightness is intended to withstand a scope of intensity variances without influencing execution and works without cooling fans or channels, so there are fewer parts to keep up. The device is tallness movable and can be coordinated with the wide assortment of other basic neonatal medicinal hardware found in healing facilities serving low-pay networks. 
In 2010, D-Rev authorized Brilliance to Phoenix Medical Systems Ltd., situated in Chennai, India, the biggest producer and supplier of neonatal care gear in the nation. The two sides consented to top the cost of Brilliance at US $\$ 400$ instead of US $\$ 3,500$ to US $\$ 10,000$ for competitive systems.

Jaipur Foot produced by the Indian NGO Bhagwan Mahaveer Viklang Sahayata Samiti (BMVSS) uses $3 \mathrm{D}$ printing technology to create above-knee and underneath knee, prostheses easily of US\$20- US\$40 contrasted and US\$12,000 in the United States.

As of now, even the least expensive models of ear devices cost in any event $\$ 500$. These devices are additionally constrained by batteries, which regularly must be changed week by week at the expense of $\$ 1$ per substitution restrictive for the poor population (Hoffmire, 2015).

Howard Weinstein, as a Canadian volunteer at Camp Hill Community Trust, a network for debilitated individuals in Botswana, set up a start-up Sun oriented Ear's in 2006 where he utilized individuals with physical and hearing incapacities, and started to plan the three parts for his sunlight based fueled listening device (McCrory, 2015). Sun oriented Ear's device is powered with 2 AA batteries that utilize a sunlight based fueled docking station. The recharger costs the same as ordinary batteries $(\$ 1)$ to last 2-3 years. The whole unit, including amplifiers, charger, and batteries, can be sold at a benefit for under $\$ 100$. (McCrory, 2015, solarear.com.br site).

\subsection{Medical diagnostic devices}

Biosense Technologies Private Limited is an Indian therapeutic building and configuration startup developing diagnostics frameworks situated in Thane, India (biosense website). Herewith a portion of the minimal effort and effective portable test developed by this organization.

TouchB is cellphone utilizing the impact of light on hemoglobin particles to test levels in the blood. Every one of the patient needs to do is embed a finger into a clasp associated with the device and an LCD screen flashes the hemoglobin check. Uchek is a Lab Made Mobile cell phone glucose test. It can work for a restricted period even without a power supply.

Macintosh 400, GE's first compact ECG composed in India for the quickly developing neighborhood market has lower material costs, utilizing less plastic and a smaller LCD screen and less expensive work costs (Mcgregor, 2008).

The MAC 400, motivated in 2008, was at only $\$ 1,500$, rather than $\$ 10,000$ for the previous age. MAC 500 today (2017) cost not as much as US\$ 360 (alibaba website). GE's portable ECG is presently found in some American ambulances (Woodrooffe, 2012).

In 2011, GE established its first worldwide Customer Technology Center in Chengdu, in China's western areas. The Center spotlights on essential administer to the health care frameworks of developing markets, and convey item improvement groups nearer to the clients they serve by making an open, client-driven advancement biological system.

The smaller ultrasound was worked starting with no outside help in China. Vscan, the reduced and portable ultrasound costs just $\$ 1500$. Vscan as a switch advancement was later effectively sold in the U.S. market as a device for small centers or emergency vehicle administrations (currentincarmel.com website).

Api-Palu an anti-malaria drug treatment produced using natural plant extracts is less expensive than accessible anti-malaria medications with incredible inhibitory consequences for 3D7 strains of plasmodium falciparum, the causative specialist of jungle fever (Apibenin website). Programming interface Palu is a quick rate jungle fever parasite treatment, clearing the blood after here and now use on generally lower measurements. His organization, Api-Benin creates and popularizes those items.

Urine Test for Malaria (UMT) is a rapid non-blood diagnostic medical device that diagnoses malaria in less than 25 minutes using a dip-stick. The technology detects malaria parasite proteins in the urine of a patient with malaria fever need to test before treating malaria with an innovative new option, the Fyodor Urine Malaria Test".

\subsection{Education systems}

Copenhagen Institute of Interaction Design (CIID) makes impact through the plan of inventive devices (ciid.dk site). Frugal Digital institute in CIID is research group that focuses on researching methods and practices around creating digital solutions in low resource settings like that of developing economies (frugaldigital site). Herewith two tasks upheld by Frugal Digital.

The lunch box projector depends on a small USB 2.0 port to empower information input. By utilizing a $3 \mathrm{G}$ telephone, the projector had an information network and the touch screen of the cellphone is utilized as a track cushion for the route. The cellphone memory could likewise be utilized to duplicate information on to it liberating the USB port. Fieldworkers and instructors could without much of a stretch envision 
conveying one of the in their pack. Likewise the cellphone accompany a couple of extras like a tripod and remote which were additionally used to upgrade the highlights of the projector.

In 2010, the Indian government reported the improvement of the Aakash tablet to give ease PCs to the country's developing understudy populace (grassrootstechnology and akashtablet websites).

It doled out the Indian Institute of Technology (IIT) Rajasthan the undertaking of developing the initial 100,000 tablets at the US\$35 value point. IIT Rajasthan took after an open offer process and chose the most minimal bidder (DataWind) among all offers regarded qualified. The Aakash tablet can be credited to the careful endeavors on part of Raja Singh Tuli and Suneet Singh Tuli siblings.

In mid-2011, the administration likewise declared that there would be two variants of the tablet: Aakash PCs, sponsored by the legislature and circulated to students at US $\$ 35$, and the Ubi Slate 7, economically accessible at US\$60.

\subsection{Moladi construction}

The organization established by Hennie Botes from South Africa has established a new method for building (moladi website).

Botes worked with a synthetic designer to figure a substance which blended with the solid, circulated air through the divider, guaranteed it was waterproof and gave the divider better heat properties contrasted with square structures. This blend is currently licensed as "MoladiCHEM".

This underlying development in developing markets was combined in the late 2000s, amid which time Moladi extended its system of accomplices on the African landmass, and in India. Today, Moladi assemble reasonable lodging in Italy and Spain (moladi website).

\section{Grassroots innovation}

Grassroots innovations reinforce the strengthening of BoP by proposing minimal effort and proficient items to needs raised by people.

\subsection{Mitti Cool}

Mitti Cool (mitti implies "earth" in Hindi) is a fridge made solely from clay, which utilizes the common cooling-impact delivered while evaporizing water, and it can hold vegetables new in up to seven days (Radjou et al, 2012). Water from the upper chambers dribbles down along within the fridge, evacuates the heat and leaves the chambers cool. The water is put away in the upper chamber and can really be utilized for drinking-water through a small fixture. The ice chest, which costs around US\$50, was a hit.

\subsection{Solar-Powered Tuki}

The Solar Tuki is a sun-based controlled white LED light to supplant lamp oil filled lamps as the predominant type of lighting apparatus utilized in Nepal's poorest networks (gsenergy.eu/solar-tuki/ site) The Solar Tuki is controlled by batteries that are revived with a small sun based board. Every unit has an extra usefulness that stretches out to charging cell phones and fueling small radios. The Solar Tuki gives a perfect, moderate, and safe contrasting option to the more common, risky, and costly lamp oil tukis (lights).

Ecological Camps for Conservation Awareness (ECCA) gave Solar Tuki sets, mass charging and upkeep preparing to 4 towns of Lothar specifically Lo-ling, Gundi, Cheuding, and Kalitar. Students, instructors, and guardians of 4 schools assembled on June 6, 2016.

\subsection{Toyola cookstove}

Ghana is the biggest per capita buyer of charcoal in West Africa. Cooking with charcoal adds to carbon dioxide emissions and indoor air contamination. Numerous Ghanaians can't stand to buy a gas stove for their homes, doing the change to cleaner energy troublesome (greeneconomycoalition website).

Toyola started by Suraj Wahab and Ernest Kyei (Darko Osei, 2010), fabricates and offers energy effective cookstoves in urban and provincial Ghana. The stoves utilize standard charcoal, however, are $40 \%$ more proficient than the conventional stoves utilized in the area. This lessens the measure of charcoal expected to cook, which likewise diminishes carbon dioxide outflows and spares families' cash. The Toyola cook stove is fitted with an earthenware liner to enhance eco-friendliness by half in the examination with the conventional coal pot. Toyola has prepared and made work for more than 300 artisans in Ghana.

Business is produced along the entire value chain which includes scrap providers, stove producers, suppliers, and retailers. 
The metal piece providers circumvent searching or purchasing the piece to pitch it to Toyola. The piece metal constitutes a vital segment of the cookstoves.

Toyola underpins artisans to have practical experience in developing one of the 26 sections that make up the coal pot. In the course of recent long stretches of the task, the organization appraises that it has provided around 35,000 family units in Ghana.

\subsection{Kansai Plascon, paint repelling mosquitos}

The organization was established in 2001 as Freeworld Coatings and situated in Sandton, South Africa with activities in Botswana, Malawi, Namibia, Swaziland, Zambia, China, and Australia.

Kansai Plascon (fromer Freeworld Coatings Ltd) developed, fabricated, marketed, and dispersed beautiful, car, and mechanical coatings in Southern Africa. Kansai paints gained from Sumitomo Chemical the know-how arequested that Kansai Plascon build up the anti-agents item for paints. The anti-agents paints were developed and sold in South Africa and acquainted in Malaysia with scuffle against dengue fever (Tanigushi, 2016).

\section{Conclusion}

Inclusive innovation in developing nations makes quicker and wider the states of better living conditions and economic improvement. The diffusion of pro inclusive, frugal and grassroots innovations, in education, telecommunication, energy and health, will generate an improved sustainable economic growth.

A minister for National Inclusive Innovation (NIIP) will have the power, the budget and the integrative duty required keeping in mind the end goal to execute his policy with better odds of achievement. A coherence office prevents regulatory failures because of different policies contradict each other.

\section{References}

Backaler J. , (2010). Haier: A Chinese Company That Innovates. Forbes, Jun 17, 2010

https://www.forbes.com/sites/china/2010/06/17/haier-a-chinese-company-thatinnovates/\#26a30d55648a

Betts A., Bloom L., and Weaver N., (2015). Refugee Innovation. Humanitarian innovation that starts with communities. .The Humanitarian Innovation Project, University of Oxford, July 2015 with support from the World Humanitarian Summit.

https://www.rsc.ox.ac.uk/refugee-innovation-humanitarian-innovation-that-starts-withcommunities/refugee-innovation-web-5-3mb-1.pdf

Codagnone 2009;

Darko Osei R. ,(2010). Toyola Charcoal Stove: Improving the Environment and Health of the Poor in Ghana. Growing inclusive markets UNDP Case studies. Enterprise Class • MSME http://www.growinginclusivemarkets.org/media/cases/Ghana_Toyola_2010.pdf

D-Rev , 2014. Final Report on Expanding Accessibility of Affordable User-Centric Phototherapy Devices for Neonates with Severe Jaundice D-Rev , August 2014

http://www.ipekpp.com/admin/upload_files/Report_2_20_Expanding_1466650459.pdf

Duysters G., Jacob J., Lemmens C. and Jintian Y. , (2009). Internationalization and technological catching up of emerging multinationals: a comparative case study of China's Haier group. Industrial and Corporate Change, Volume 18, Number 2, pp. 325-349. https://myweb.rollins.edu/tlairson/asiabus/haierglb.pdf).

Heeksa R., Fosterb C. and Nugrohoa Y., (2014). Introduction of New models of inclusive innovation for development. Innovation and Development, 2014 Routledge.

http://dx.doi.org/10.1080/2157930X.2014.928982

Mashelkar, R. A., (2014). Accelerated Inclusive Growth through Inclusive Innovation, presentation at the OECD-Growth Dialogue Symposium on Innovation and Inclusive Growth, 20 March 2014, Paris, www.oecd.org/sti/inno/Session_3_Mashelkar_Keynote.pdf .

McCrory K., (2015). Open source solar-powered hearing aids. Virgin. 22 June 2015

https://www.virgin.com/virgin-unite/entrepreneurship/open-source-solar-powered-hearing-aids

NIC ( 2013). Report to the People Third Year. National Innovation Council Government of India. November 2013

innovationcouncilarchive.nic.in/index.php?option=com_content\&view=article\&id=346:report-tothe-people-2013\&catid=90:ninc-annual-reports\&Itemid $=109$

OECD (2015). Innovation Policies for Inclusive Development : Scalling up Inclusive Innovations. OECD 2015.

88 | P a g e 
https://www.oecd.org/innovation/inno/scaling-up-inclusive-innovations.pdf OECD 2013

Paunov C.,(2013). Innovation and Inclusive Development. Conference discussion report, 21 November 2013. Cap Town, South Africa OECD. Revision February 2013

https://www.oecd.org/sti/inno/oecd-inclusive-innovation.pdf

Radjou N., Prabhu J. Ahuja S., (20120. Jugaad Innovation. Jossey-Bass A Wiley Imprint, San Francisco, CA

St. John J., (2012). India’s Smart Grid Comes Alive . Green Media. March 09, 2012 https://www.greentechmedia.com/articles/read/indias-smart-grid-comes-alive

UN, (2016). The Role of Technology and Innovation in Inclusive and Sustainable Industrial Development. Industrial Development Report 2016. United Nations

https://www.unido.org/fileadmin/user_media_upgrade/Resources/Publications/EBOOK_IDR2016_ FULLREPORT.pdf

UNICEF (2016). UNICEF partners with University of Nairobi to innovate for children and young children., UNICEF, 13 May 2016

https://www.unicef.org/esaro/5440_ken2016_university-partnership.html

\section{Websites}

akashtablet websites

amazon.in/Godrej-ChotuKool-Mobile-Beverage-Cooler/dp/B01NAHTWVM

atelier.bnpparibas/en/smart-city/article/india-startup-village-aims-transforming-innovationentrepreneurship

biosense.in

creec.or.ug/

farmdrive.co.ke

fraunhofer.pt/en/fraunhofer_portugal/news/news_archive/gra_ict4d_project_launched.html

godrejandboyce.com/godrejandboyce/GnB_about.aspx?id=16\&menuid=4112

grassrootsinnovations.org/about/

greeneconomycoalition.org/glimpses/efficient-cooking-stoves-ghana-china

insidephilanthropy.com/grants-for-global-development/omidyar-network-grants-for-globaldevelopment.html

gsenergy.eu/solar-tuki/

nnovationcouncilarchive.nic.in/index.php?option $=$ com content $\&$ view $=$ category \&layout $=$ blog $\&$ id $=$ $\underline{8 \& \text { Itemid }=10}$

lutw.org/site

malariaworld.org/blog/press-release-vestergaard-world-health-organizations-vector-controladvisory-group-supports

m-kulima.co.ke

mobisante website

siemens.com/global/en/home/products/energy/energy-automation-and-smart-grid.html

siemens.com/innovation/en/home/pictures-of-the-future/energy-and-efficiency/smart-grids-andenergy-storage-microgrid-in-brooklyn.html

soapen.com/

solarear.com.br

technologyreview.com/s/426336/medicine-needs-frugal-innovation/

technologyreview.com/s/424034/solar-disinfecting-device-for-the-developing-world/

unicefstories.org/tag/kenya/ 